\title{
HSP90 inhibits apoptosis and promotes growth by regulating HIF-1 $\alpha$ abundance in hepatocellular carcinoma
}

\author{
XIN LIU ${ }^{1}$, SHUDA CHEN ${ }^{1}$, JIANFENG TU ${ }^{2}$, WENWEI CAI ${ }^{2}$ and QIURAN XU ${ }^{2}$ \\ Departments of ${ }^{1}$ Neurosurgery and ${ }^{2}$ Emergency, Zhejiang Provincial People's Hospital, \\ Hangzhou, Zhejiang 310014, P.R. China
}

Received March 25, 2015; Accepted January 26, 2016

DOI: 10.3892/ijmm.2016.2482

\begin{abstract}
Heat shock protein (HSP)90 functions as a general oncogene by targeting several well-known oncoproteins for ubiquination and proteasomal degradation. However, the clinical significance of HSP90, as well as the mechanisms responsible for the tumor-promoting effects of HSP90 in hepatocellular carcinoma (HCC) remain unclear. In this study, HSP90 and hypoxia-inducible factor (HIF)-1 $\alpha$ expression in 60 samples of HCC tissues and matched normal tumor-adjacent tissue were assessed using immunohistochemistry (IHC) or western blot analysis. Flow cytometry, BrdU cell proliferation assay, caspase-3/7 activity assay and MTT assay were used to detect the apoptosis and proliferation of the HCC cells. The regulatory effect of HSP90 on HIF-1 $\alpha$ in the HCC cells was confirmed by immunofluorescence staining, western blot analysis and RT-qPCR. The interaction between HIF-1 $\alpha$ and HSP90 was analyzed by co-immunoprecipitation. A subcutaneous tumor xenograft model in nude mice was established and TUNEL assay was performed to evaluate cancer cell apoptosis and growth in vivo. We found that HSP90 expression was higher in the HCC tissues than in the normal tissues and that a high HSP90 expression correlated with poor clinicopathological characteristics, including venous infiltration, an advanced TNM stage and high pathological grading. Furthermore, we confirmed that patients with a negative expression of HSP90 had an improved 3-year survival, and that HSP90 was an independent factor for predicting the prognosis of patients with HCC. We demonstrated that HSP90 promoted HCC by inhibiting apoptosis and promoting cancer cell growth. Pearson's correlation coefficient analysis indicated that HSP90 expression positively correlated with HIF- $1 \alpha$ protein expression in the HCC tissues. Furthermore, we found that HSP90
\end{abstract}

Correspondence to: Dr Qiuran Xu, Department of Emergency, Zhejiang Provincial People's Hospital, 158 Shangtang Road, Hangzhou, Zhejiang 310014, P.R. China

E-mail:windway626@sina.com

Key words: heat shock protein 90, hepatocellular carcinoma, hypoxia-inducible factor- $1 \alpha$, apoptosis, growth arrest regulated HIF-1 $\alpha$ protein abundance by inhibiting the ubiquitination and proteasomal degradation of HIF-1 $\alpha$ in HCC cells. Additionally, the upregulation of HIF-1 $\alpha$ expression partially abrogated HSP90 siRNA-induced HCC cell growth arrest and apoptosis in vitro and in vivo. These results indicate that HSP90 may be used as a prognostic marker and that HIF-1 $\alpha$ may be one of the potential therapeutic targets of HSP90 in HCC.

\section{Introduction}

Hepatocellular carcinoma (HCC) is one of the most common malignancies affecting the liver and the third and fifth leading cause of cancer-related mortality worldwide in males and females, respectively (1). The incidence of HCC has increased in recent years; however, satisfactory curative effects have not yet been achieved (2). Thus, it is important to elucidate the precise molecular mechanisms responsible for the development of HCC, and to identify novel therapeutic targets (2).

The heat shock proteins (HSPs) are highly conserved molecular chaperones typically expressed in response to environmental stress factors, including invading pathogens, toxins and heat (3). Their principal function is to prevent protein denaturation and misfolding. The HSPs have been classified into the following $5 \mathrm{HSP}$ families, according to molecular mass and homology: small HSPs (sHSPs) include HSP100, HSP90, HSP70 and HSPP60 $(3,4)$. HSP90 plays an important role in the metastasis, invasion and vascularization of tumors, particularly in time course of cell cycles, the proliferation of tumor cells and in maintaining the function of a number of carcinogenic proteins involved in the signal transduction pathway of cell apoptosis $(5,6)$. HSP90 has been found to be overexpressed in HCC (7). Yano et al (8) demonstrated that a high HSP90 expression significantly correlated with tumor size, lymph node metastasis and a poor prognosis in breast cancer. In our previous study, we demonstrated that a high HSP90 expression contributed to the more aggressive phenotypes observed in colorectal cancer (CRC) (9). However, the clinical significance of HSP90 in predicting prognosis, as well as the mechanisms responsible for the tumor-promoting effects of HSP90 remain unknown.

Hypoxia is a condition in which tissues are starved of oxygen. It is a key characteristic of most tumor environments, contributing to radioresistance, chemoresistance, metastasis, angiogenesis, resistance to cell death and altered metabolism 
and genomic instability (10). Hypoxia-inducible factor (HIF), a transcription factor which plays an important role in tumorigenesis, may induce angiogenesis and drug-resistance (11). HIF-1 is a heterodimer composed of an $\mathrm{O}_{2}$-regulated HIF-1 $\alpha$ subunit and a constitutively expressed HIF-1 $\beta$ subunit (11). It has been demonstrated that HIF-1 $\alpha$ regulates glycolysis, tumor angiogenesis and the invasiveness of tumors (12-14). However, the mechanisms governing HIF-1 $\alpha$ protein stability remain poorly understood.

In the present study, we confirmed that HSP90 is an independent prognostic factor for predicting the overall 3-year survival of patients with HCC. HSP90 serves as a tumor promoter by inhibiting apoptosis and promoting the growth of HCC cells. In HCC tissues, HSP90 protein expression positively correlated with HIF-1 $\alpha$ protein expression. In addition, HSP90 interacted with HIF-1 $\alpha$ and inhibited HIF-1 $\alpha$ ubiquitination, ultimately leading to HIF-1 $\alpha$ aggregation. Notably, the antitumor effects of HSP90 siRNA were partially abrogated by the upregulation of HIF-1 $\alpha$ expression in vitro and in vivo. Our results demonstrate that HSP90 may target HIF-1 $\alpha$ by inhibiting its ubiquitination and proteasomal degradation, and inducing HCC cell growth and tumor progression.

\section{Materials and methods}

Clinical samples, expression vectors and cell lines. A total o f60 HCC tissue samples and paired normal tumor-adjacent tissue samples $(>1.5 \mathrm{~cm}$ distance from the margin of the resection) were obtained and used after obtaining written informed consent from patients at the Department of Hepatobiliary Surgery at Zhejiang Provincial People's Hospital (Hangzhou, China) between 2007 and 2010, with a median follow-up time of 32.5 months (patients were followed-up for 3 years; however, as some patients died before the 3-year period, the median follow-up time is 32.5 months). Prior to surgery, no patients had received any radiotherapy, chemotherapy or radiofrequency ablation treatments. The clinicopathological data and demographic characteristics of the patients are presented in Table I. The age of the patients ranged from 35-71 years (median, 52 years). Tumor tissue and matched normal tumor-adjacent tissue specimens were collected and immediately stored in paraformaldehyde for immunohistochemistry (IHC), as previousy described (15). The Ethics Committee of the Provincial People's Hospital approved all the study protocols according to the 1975 Declaration of Helsinki.

The cell lines, Hep3B,HepG2 and 293T cells were all obtained from the Institute of Biochemistry and Cell Biology, Chinese Academy of Sciences (Shanghai, China). All the cells were maintained in Dulbecco's modified Eagle's medium (DMEM; Gibco, Grand Island, NY, USA) supplemented with $10 \%$ fetal bovine serum (FBS; Gibco) with 100 units/ml penicillin and $100 \mu \mathrm{g} / \mathrm{ml}$ streptomycin (Sigma, St. Louis, MO, USA) and cultured in a humidified $5 \% \mathrm{CO}_{2}$ incubator at $37^{\circ} \mathrm{C}$, as previously described (15).

Control siRNA (sc-37007) and siRNA against HSP90 $\alpha / \beta$ (HSP90 $\alpha / \beta$ siRNA, sc-35610) were obtained from Santa Cruz Biotechnology (Santa Cruz, CA, USA). The retroviral vectors, pMMP-Flag-HSP90 and pMMP-HA-HIF-1 $\alpha$, were generated by inserting the respective cDNA into pMMP (Addgene). All constructs were confirmed by western blot analysis and
Table I. Correlation between heat shock protein (HSP) 90 expression and clinicopathological characteristics in hepatocellular carcinoma (HCC).

\begin{tabular}{|c|c|c|c|c|}
\hline \multirow[b]{2}{*}{$\begin{array}{l}\text { Clinicopathological } \\
\text { characteristics }\end{array}$} & \multirow{2}{*}{$\begin{array}{c}\text { Total } \\
\text { no. of } \\
\text { patients, } \\
n=60\end{array}$} & \multicolumn{2}{|c|}{ No. of patients } & \multirow[b]{2}{*}{ P-value } \\
\hline & & $\begin{array}{l}\text { HSP90- } \\
\text { positive }\end{array}$ & $\begin{array}{l}\text { HSP90- } \\
\text { negative }\end{array}$ & \\
\hline \multicolumn{5}{|l|}{ Age (years) } \\
\hline$<50$ & 16 & 4 & 12 & 0.518 \\
\hline$\geq 50$ & 44 & 16 & 28 & \\
\hline \multicolumn{5}{|l|}{ Gender } \\
\hline Male & 38 & 14 & 24 & 0.353 \\
\hline Female & 22 & 6 & 16 & \\
\hline \multicolumn{5}{|l|}{$\mathrm{HBV}$} \\
\hline Absent & 22 & 8 & 14 & 0.540 \\
\hline Present & 38 & 12 & 26 & \\
\hline \multicolumn{5}{|c|}{ Serum AFP level (ng/ml) } \\
\hline$<400$ & 10 & 4 & 6 & 0.694 \\
\hline$\geq 400$ & 50 & 16 & 34 & \\
\hline \multicolumn{5}{|l|}{ Tumor size $(\mathrm{cm})$} \\
\hline$<5$ & 32 & 11 & 21 & 0.680 \\
\hline$\geq 5$ & 28 & 9 & 19 & \\
\hline \multicolumn{5}{|l|}{ Cirrhosis } \\
\hline Absent & 11 & 7 & 4 & 0.201 \\
\hline Present & 49 & 13 & 36 & \\
\hline \multicolumn{5}{|l|}{ PVTT } \\
\hline Absent & 18 & 11 & 7 & $0.004^{\mathrm{a}}$ \\
\hline Present & 42 & 9 & 33 & \\
\hline \multicolumn{5}{|l|}{$\begin{array}{l}\text { Edmondson-Steiner } \\
\text { grading }\end{array}$} \\
\hline $\mathrm{I}+\mathrm{II}$ & 18 & 6 & 12 & $0.006^{\mathrm{a}}$ \\
\hline III+IV & 42 & 30 & 12 & \\
\hline \multicolumn{5}{|l|}{ TNM tumor stage } \\
\hline $\mathrm{I}+\mathrm{II}$ & 36 & 17 & 19 & $0.010^{\mathrm{a}}$ \\
\hline III + IV & 24 & 3 & 21 & \\
\hline
\end{tabular}

HBV, hepatitis B virus; AFP, alpha-fetoprotein; TNM, tumor-nodemetastasis; PVTT, portal vein tumor thrombus. ${ }^{\text {aS }}$ Statistically significant.

sequencing analysis. The day prior to transfection, $5-6 \times 10^{6} 293 \mathrm{~T}$ cells were seeded in 100-mm dishes, as previously described (15). Three plasmids, $1.5 \mu \mathrm{g}$ pMD.MLV, $0.5 \mu \mathrm{g}$ pVSV.G and $2 \mu \mathrm{g}$ of the relevant retroviral vectors, were transfected into the cells using Effectene Transfection reagent (Qiagen, Valencia, CA, USA), as previously described (15). The medium containing the retroviruses was collected $72 \mathrm{~h}$ following transfection. Viral transduction was performed by incubating the cells with the viral supernatant (25\%) supplemented with Polybrene (8 $\mu \mathrm{g} /$ $\mathrm{ml}$; Santa Cruz Biotechnology) overnight at $37^{\circ} \mathrm{C}$, as previously described (15). Further experiments were performed $72 \mathrm{~h}$ after viral transduction, as previously described (15). 
Immunohistochemical analysis. IHC was performed on $5-\mu \mathrm{m}$-thick sections from formalin-fixed, paraffin-embedded tissue samples applied to coated slides, as described in a previous study (16). The following antibodies were used together with a streptavidin-peroxidase (SP) conjugate (SP-IHC method): HSP90 (ab13492; 1:150) and HIF-1 $\alpha$ (ab85886; 1:200) (both from Abcam, Cambridge, MA, USA). IHC was performed as previously described (17). The percentage of positive tumor cells or hepatocytes was graded as per the following criteria: $0,<10 \%$; $1,10-30 \% ; 2,30-50 \% ; 3,>50 \%$, as previously described (18).

Reverse transcription-quantitative polymerase chain reaction (RT-qPCR). The following primers were used: HSP90 sense, 5'-ATGGCAGCAAAGAAACAC-3' and antisense, 5'-GTATC ATCAGCAGTAGGGTCA-3'; and HIF-1 $\alpha$ sense, 5'-GAACC TGATGCTTTAACT-3' and antisense, 5'-CAACTGAT CGAAGGAACG-3'. The PCR amplification for the quantification of the HSP90 and HIF-1 $\alpha$ mRNA was performed using a SYBR ${ }^{\circledR}$ Premix Ex Taq $^{\mathrm{TM}}$ II (Perfect Real-Time) kit (Takara Bio, Otsu, Japan) and an ABI PRISM 7300 Sequence Detection system (Applied Biosystems, Foster City, CA, USA), as previously described (19).

Western blot analysis. The following primary antibodies were used for western blot analysis: HSP90 (ab13492; 1:1,000), HIF-1 $\alpha$ (ab85886; 1:1,000) (both from Abcam), Akt (sc-5298; 1:1,000), CDK4 (sc-260; 1:1,000), ubiquitin (sc-8017; 1:500) and $\beta$-actin (sc-47778; 1:1,000) (all from Santa Cruz Biotechnology). Horseradish peroxidase-conjugated goat anti-rabbit or anti-mouse secondary antibodies (1721019 and 1708242; Bio-Rad, Hercules, CA, USA) were used at a 1:1,000-1:5,000 dilution and the results were detected using Western Blotting Luminol reagent (sc-2048; Santa Cruz Biotechnology).

Immunofluorescence (IF) staining. The HCC cells were fixed with $3 \%$ paraformaldehyde and then permeabilized with $0.2 \%$ Triton $\mathrm{X}-100$, as previously described (15). The fixed cells were subsequently incubated with the HIF-1 $\alpha$ (1:500) primary antibody. An Alexa Fluor-conjugated IgG (Invitrogen, Carlsbad, CA, USA) was used as the secondary antibody. A LSM 5 Pascal laser scanning microscope (Zeiss, Oberkochen, Germany) was used to capture fluorescence confocal images with a $\mathrm{x} 40$ lens and LSM 5 PASCAL software (version 4.2 $\mathrm{SP} 1$; Zeiss) was then used to scan the images, as described in a previous study (15).

Co-immunoprecipitation (co-IP). Flag (F1804; Sigma) and hemagglutinin (HA) (12CA5; Roche, Indianapolis, IN, USA) antibodies were used in the co-IP assays. Immunoprecipitation buffer was used to obtain total protein lysate. The Bio-Rad DC ${ }^{\mathrm{TM}}$ protein assay reagent $\mathrm{A} / \mathrm{B} / \mathrm{S}$ (Bio-Rad) was used to quantify the total protein concentration of the supernatants. Total protein $(500 \mu \mathrm{g})$ was mixed with $1 \mu \mathrm{g}$ of the primary antibody, or IgG as previously described (15), and the mixture was shaken for $4 \mathrm{~h}$ at $4^{\circ} \mathrm{C}$. The beads (Protein G Sepharose 4 Fast Flow; GE Healthcare Life Sciences, Piscataway, NJ, USA) were then added to the mixture and shaken at $4^{\circ} \mathrm{C}$ for $2 \mathrm{~h}$. Subsequently, the beads were collected by centrifugation $\left(500 \times \mathrm{g}, 4^{\circ} \mathrm{C}\right)$ and washed 3 times using immunoprecipitation buffer, as previously described (15). Sample loading buffer (5X) was mixed with the beads and boiled for $10 \mathrm{~min}$. The supernatant was used for western blot analysis.

CHX chase assays were also performed to analyze the HSP90-mediated downregulation of HIF-1 $\alpha$ in the Hep3B cells in which HSP90 was knocked down and in the controls. Cycloheximide (CHX; ab120093), a protein synthesis inhibitor, was obtained from Abcam. Furthermore, MG132 (a proteosome inhibitor; ab141003; Abcam) was used to determine whether it can prevent the downregulation of HIF-1 $\alpha$.

Cell viability and proliferation assays. In the present study, 3-(4, 5-dimethylthiazol-2-yl)-2,5-diphenyl tetrazolium bromide (MTT; Roche) assay was used to assess cell viability at 24, 48 and $72 \mathrm{~h}$. In addition, the HCC cells were seeded into 96-well plates at 3,000-5,000 cells/well for $24 \mathrm{~h}$ and 5-bromodeoxyuridine (BrdU) assay (chemiluminescent) (Roche) was used to assess cell proliferation, as previously described (17).

Cell apoptosis. The level of apoptosis was analyzed using an Annexin V-FLUOS staining kit (Roche), as previously described (20). Caspase-3/7 activity was analyzed using an Apo-ONE ${ }^{\circledR}$ Homogeneous Caspase-3/7 assay (Promega, Madison, WI, USA), as described in the study by Zheng et al (21).

Flow cytometry. We analyzed cell apoptosis using the Annexin V-FLUOS staining kit (obtained from Roche) after a 48-h transfection. Briefly, the samples were analyzed using a BD FACSCanto II flow cytometer (Becton-Dickinson, Franklin Lakes, NJ, USA). Three independent repeated experiments were performed.

In vivo experiments. We used 4-6 week-old female BALB/c nude mice $(n=18$; Centre of Laboratory Animals at Zhejiang Provincial People's Hospital, Hangzhou, China) to establish a xenograft tumor model. The mice ( 2 animals/cage) were housed in sterilized cages at a constant humidity and temperature and the mice were fed a regular autoclaved chow diet with water ad libitum, as previously described (21). As described in American Type Culture Collection (ATCC), HepG2 is not a tumorigenic cell line; we thus inoculated $4-5 \times 10^{6}$ Hep3B cells subcutaneously into the flank of each nude mouse. The tumor volume was determined by measuring two dimensions and was calculated as follows: tumor volume $=$ length $\mathrm{x}$ width $\mathrm{x}$ widt $\mathrm{h} / 2$, as previousy described (15). After 3 weeks, we used a terminal deoxynucleotidyl transferase-mediated dUTP nickend labeling (TUNEL) assay kit (4810-30-K; R\&D Systems, Minneapolis, MN, USA) to detect the amount of apoptosis in the tumor tissues according to the manufacturer's instructions. Furthermore, all animal protocols were approved by the Institutional Animal Care and Use Committee of Zhejiang Provincial People's Hospital.

Statistical analysis. All data are presented as the means \pm SEM. SPSS software (SPSS, Inc., Chicago, IL, USA) was used for the multivariate Cox regression analysis and the Pearson Chi-square tests. GraphPad Prism 5 software (GraphPad Software, Inc., San Diego, CA, USA) was used to evaluate statistical significance. A value of $\mathrm{P}<0.05$ was considered to indicate a statistically significant difference. 

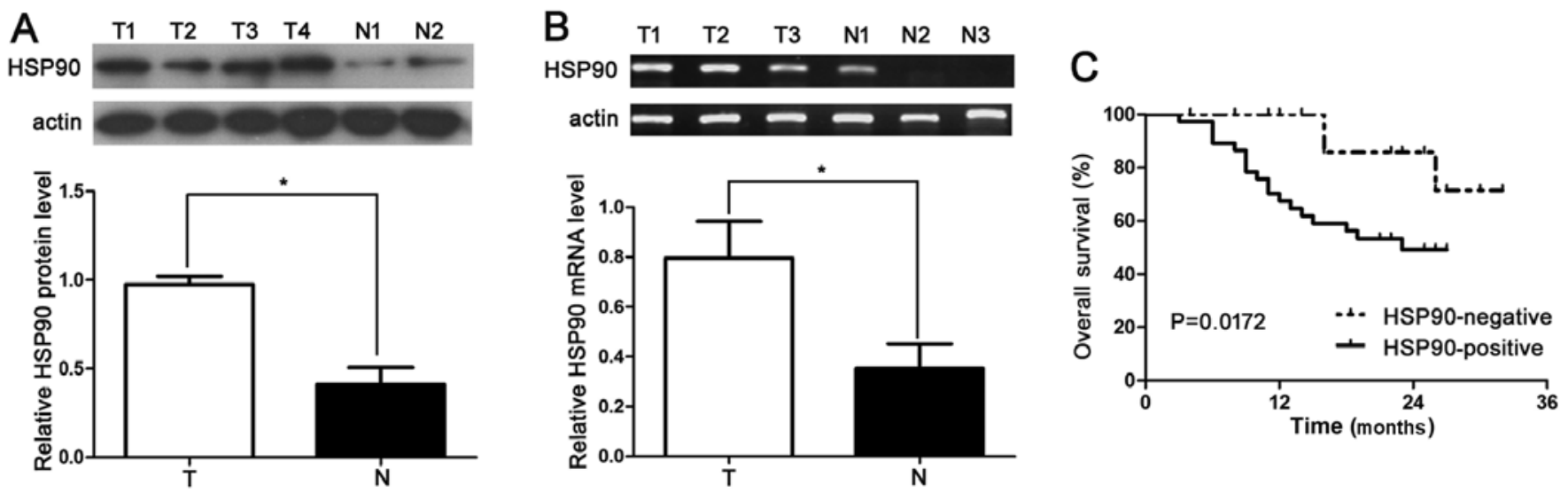

Figure 1. Expression of heat shock protein (HSP)90 and its clinical significance in hepatocellular carcinoma (HCC). (A) Western blot analysis of HSP90 expression in cancer $(\mathrm{T})$ and matched tumor-adjacent tissues $(\mathrm{N})$ is shown. Quantification of the data suggested that HSP90 protein expression in HCC tissues was significantly higher than that in the normal tumor-adjacent tissues. $n=20$; values are depicted as the means \pm SEM; ${ }^{*} \mathrm{P}<0.05$ by $\mathrm{t}$-test. (B) HSP90 mRNA levels in cancer $(\mathrm{T})$ and matched tumor-adjacent tissues $(\mathrm{N})$ were determined by RT-qPCR. Quantification of the data showed that HSP90 mRNA in HCC tissues was significantly higher than that in the normal tumor-adjacent tissues. $n=20$; values are depicted as the means $\pm \mathrm{SEM}$; ${ }^{*} \mathrm{P}<0.05$ by $\mathrm{t}$-test. (C) Kaplan-Meier survival curves showing overall 3-year survival for HCC patients in accordance with their HSP90 protein expression. The HSP90-negative expression group (n=40), IHC score of HSP90 =0; HSP90-positive expression group ( $\mathrm{n}=20$ ), IHC score of HSP90=1-3; ${ }^{*} \mathrm{P}<0.05$ by log-rank test.

Table II. Univariate and multivariate analysis of factors associated with 3-year overall survival.

\begin{tabular}{lrl}
\hline Parameter & HR & P-value \\
\hline Univariate analysis & & \\
$\quad$ Tumor size (cm) & 6.041 & $0.016^{\mathrm{a}}$ \\
Edmondson-Steiner grading & 0.032 & $0.006^{\mathrm{a}}$ \\
TNM stage & 75.634 & $0.040^{\mathrm{a}}$ \\
HSP90 (high vs. lower) & 22.298 & $0.0172^{\mathrm{a}}$ \\
Multivariate analysis & & \\
Edmondson-Steiner grading & 18.669 & $0.000^{\mathrm{a}}$ \\
TNM stage & 3.576 & $0.017^{\mathrm{a}}$ \\
HSP90 (high vs. lower) & 4.230 & $0.040^{\mathrm{a}}$ \\
\hline
\end{tabular}

${ }^{\mathrm{a}} \mathrm{P}<0.05$. TNM, tumor-node-metastasis; HSP90, heat shock protein 90.

\section{Results}

Clinical significance of increased HSP9O expression in HCC tissues. The protein expression of the HSP90 was determined by the immunostaining of 60 pairs of cancerous and matched para-carcinoma tissue samples, in order to investigate the clinical significance of HSP90 in HCC. HSP90 immunoreactivity was considered as either positive (scores 1-3) or negative (score 0). In these tissues, HSP90 expression was detected in $20(33.3 \%)$ of the HCC specimens; however, only $8(13.3 \%)$ of the normal tumor-adjacent tissues exhibited a positive HSP90 signal $(\mathrm{P}<0.05)$. In addition, 20 samples were subjected to RT-qPCR and western blot analysis for HSP90 expression. We found that the HSP90 protein level in the HCC tissues was significantly higher than that in the normal tissues $(\mathrm{P}<0.05$; Fig. 1A and B). The results of the Pearson Chi-square test indicated that the increased HSP90 expression in HCC tissues was significantly associated with venous infiltration $(\mathrm{P}=0.004)$, an advanced tumor stage [tumor-node-metastasis (TNM) stage III + IV; $\mathrm{P}=0.010]$ and a high histological grade (EdmondsonSteiner grade III + IV; $\mathrm{P}=0.006$ ) (Table I).

Negative expression of HSP90 correlates with an improved 3-year survival for patients with HCC. To confirm the role of HSP90 in evaluating the prognosis of patients with $\mathrm{HCC}$, the immunohistostaining of HSP90 was performed to determine the correlation between HSP90 expression and the 3-year patient survival. We used the overall 3-year patient survival data to analyze cases with negative and positive HSP90 staining by constructing Kaplan-Meier survival curves. Our data indicated that the overall 3-year survival in the HSP90negative expression group was $63.75 \%$. In comparison, the overall 3-year survival in the HSP90-positive expression group was $45.46 \%$. The patients in the HSP90-positive expression group $(n=20)$ had a markedly poorer prognosis than those in the HSP90-negative expression group ( $\mathrm{n}=40 ; \mathrm{P}=0.0172$; Fig. 1C). These data suggest that in HCC, HSP90 may act as a potential prognostic marker. Additionally, HSP90 expression is an independent factor for predicting the 3-year overall survival in patients with $\mathrm{HCC}(\mathrm{P}=0.0172$; Table II).

HSP90 induces the proliferation and inhibits the apoptosis of HCC cells. In our previous study, we demonstrated that the protein expression of HSP90 may be associated with the metastasis, development and invasion of human CRC, and that its synergistic effects may play a role in the development of CRC (9). In the present study, we aimed to determine whether HSP90 may serve as a cancer-promoting gene in HCC by promoting cell proliferation and inhibiting apoptosis. HSP90 protein expression was downregulatd by HSP90 siRNA or it was increased by Flag-HSP90 (ectopically expressing a flag-tagged HSP90), in the Hep3B and HepG2 cells, respectively (Fig. 2A). As determined by caspase-3/7 activity assays, apoptosis assays 

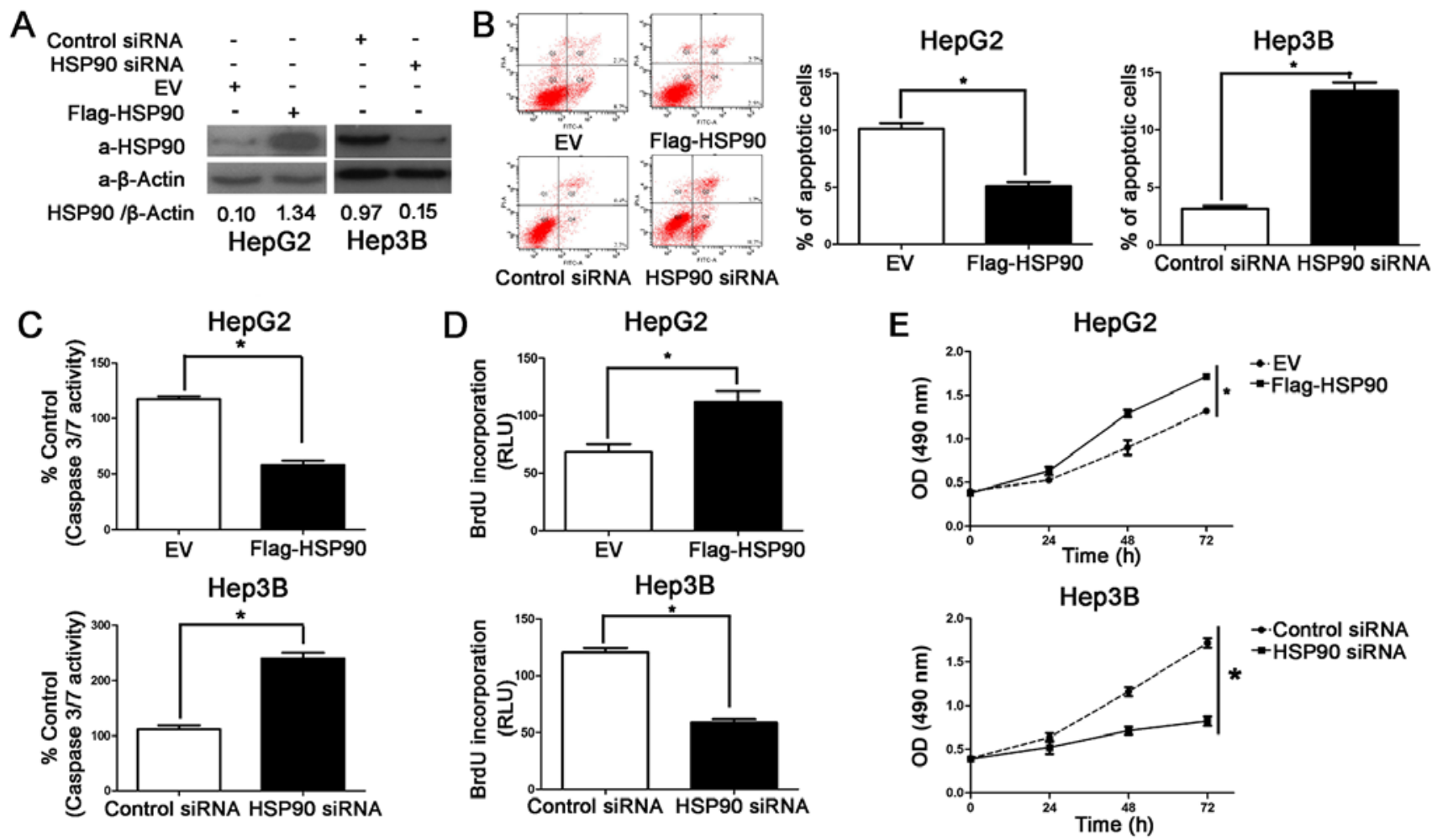

Figure 2. Heat shock protein (HSP90) regulates the proliferation and apoptosis of hepatocellular carcinoma (HCC) cells. (A) Hep3B and HepG2 cells were transfected with HSP90 siRNA and Flag-HSP90, respectively, and then subjected to western blot analysis for HSP90. The data are representative of multiple repeats with similar results. (B) Flow cytometric quantification of the apoptotic cell population. HSP90 knockdown increased the percentage of apoptotic Hep3B cells compared with the control cells, and HSP90-overexpressing HepG2 cells were composed of a smaller subset of apoptotic cells. * $<0.05$ by t-test; $\mathrm{n}=3$ repeats with similar results. (C) The activity of caspases-3 and -7 was downregulated following HSP90 overexpression in HepG2 cells and upregulated after HSP90 knockdown in Hep3B cells. ${ }^{*} \mathrm{P}<0.05$ by t-test; $\mathrm{n}=3$ repeats with similar results. (D) Cell proliferation was measured by BrdU assay which was inhibited by HSP90 knockdown in Hep3B cells and promoted by HSP90 overexpression in HepG2 cells. * P<0.05 by t-test; n=3 repeats with similar results. (E) Using MTT assays, the viability of HepG2 cells was enhanced after HSP90 overexpression, and HSP90 knockdown reduced the viability of Hep3B cells. ${ }^{*}<<0.05$ by two-way ANOVA; $n=3$ repeats with similar results. Values are depicted as the means \pm SEM.

and flow cytometry, the overexpression of HSP90 prevented the HepG2 cells from undergoing apoptosis and the knockdown of HSP90 induced the apoptosis of the Hep3B cells $(\mathrm{P}<0.05$, respectively; Fig. 2B and C). MTT and BrdU assays were also used to determine the effects of HSP90 on cancer cell viability and proliferation, respectively. As expected, the knockdown of HSP90 decreased the viability and proliferation of the Hep3B cells and HSP90 overexpression enhanced the viability and proliferation of the HepG2 cells ( $\mathrm{P}<0.05$; Fig. 2D and $\mathrm{E})$. The HepG2 cells exhibited a lower basal expression level of HSP90 than the Hep3B cells. Thus, our data indicated that the Hep3B cells had more baseline apoptosis and less proliferative ability than the HepG 2 cells (as indicated by our preliminary experiments; data not shown). Thus, HSP90 exerts promotes the development of HCC effect by inhibiting the apoptosis and promoting the growth of cancer cells.

HSP90 positively correlates with HIF-1 $\alpha$ protein expression in HCC tissues. Since HIF-1 $\alpha$ overexpression has been reported in HCC (22), we examined the correlation between HSP90 and HIF-1 $\alpha$ in 60 HCC tissue samples using IHC. HSP90 and HIF-1 $\alpha$ immunoreactivity was considered as either positive (scores 1-3) or negative (score 0 ). The protein expression of HSP90 and HIF-1 $\alpha$ in the cancer tissues was higher than that in the paired para-carcinoma tissues $(\mathrm{P}<0.05)$. In addition, the IHC scores that were used for the semi-quantitative analysis of HSP90 and HIF-1 $\alpha$ expression revealed a strong positive correlation between HSP90 and HIF-1 $\alpha$ in the HCC tissues $(\mathrm{r}=0.420$; $\mathrm{P}<0.05$; Fig. 3).

HSP90 regulates HIF-1 $\alpha$ abundance in HCC cells. To examine the downstream target genes of HSP90 in HCC, the Hep3B and HepG2 cells were transfected with HSP90 siRNA and Flag-HSP90, respectively. Western blot analysis was performed to detect Akt, CDK4 and HIF-1 $\alpha$. Akt and CDK4 are confirmed target proteins of HSP90 $(23,24)$. HIF-1 $\alpha$ acts as an activating transcription factor involved in the regulation of apoptosis, proliferation and cell growth (25). The overexpression of HSP90 led to the accumulation of Akt and CDK4 in the HepG2 cells and transfection with HSP90 siRNA decreased the levels of both proteins in the Hep3B cells (Fig. 4A). Furthermore, we found that the knockdown of HSP90 decreased the protein level of HIF-1 $\alpha$ in the Hep3B cells and that the overexpression of HSP90 increased the HIF-1 $\alpha$ protein levels in the HepG2 cells (Fig. 4A), whereas the HIF-1 $\alpha$ mRNA levels were only either slightly increased or slightly decreased (Fig. 4B). In addition, IF staining for HIF-1 $\alpha$ revealed that the average level of HIF-1 $\alpha$ in the Flag-HSP90-transfected HepG2 cells was significantly higher than that in the control cells $(\mathrm{P}<0.05$; Fig. 4C). However, the average level of HIF-1 $\alpha$ in the HSP90 siRNA-transfected Hep3B cells was significantly lower than the HIF-1 $\alpha$ levels in the control cells $(\mathrm{P}<0.05$; Fig. 4C). These 

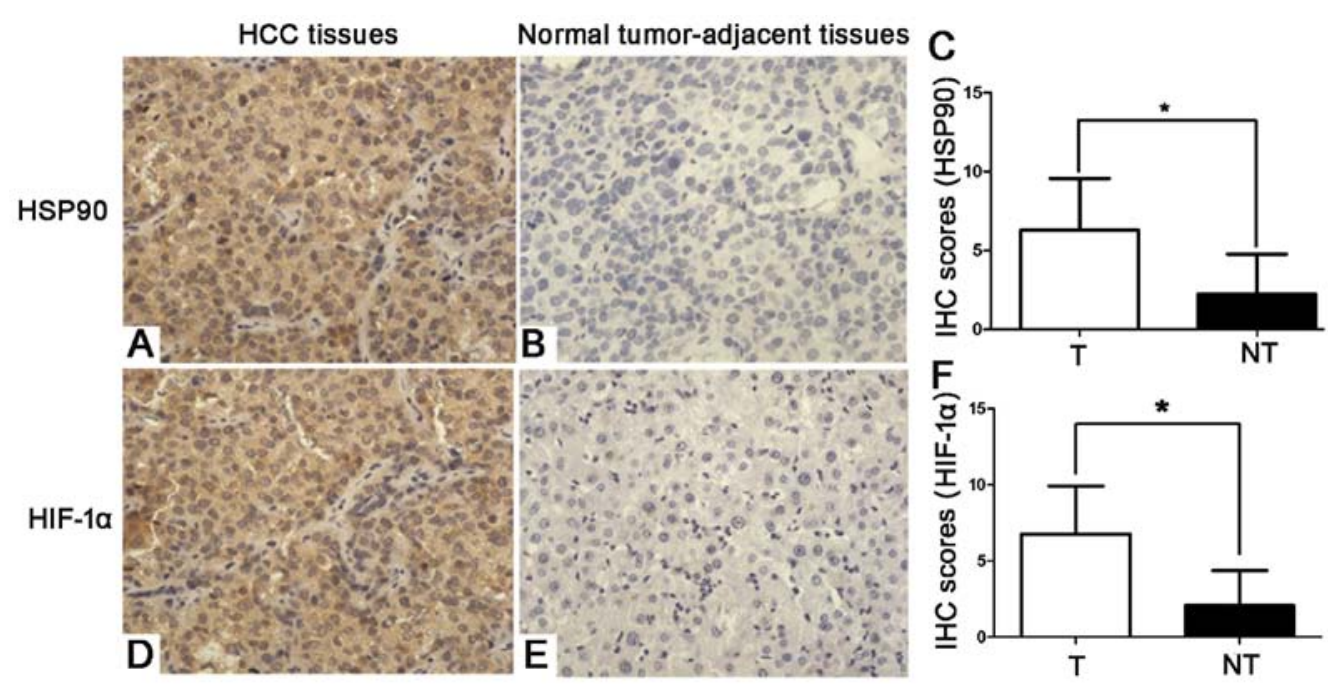

Figure 3. Immunohistochemical analyses of heat shock protein (HSP90) and its correlation with hypoxia-inducible factor (HIF)-1 $\alpha$ protein in hepatocellular carcinoma (HCC). The expression pattern of (A) HSP90 in HCC tumor tissues and (B) HSP90 in adjacent normal tissues and (D) HIF-1 $\alpha$ protein in HCC tumor tissues and (E) HIF-1 $\alpha$ protein in adjacent normal tissues, by immunohistochemistry. The protein expression of HSP90 and HIF-1 $\alpha$ in cancer tissues (T) was significantly higher than that in paired non-cancerous tissues (NT; C and F; $* \mathrm{P}<0.05$ ). Scale bar, $100 \mu \mathrm{m}$.

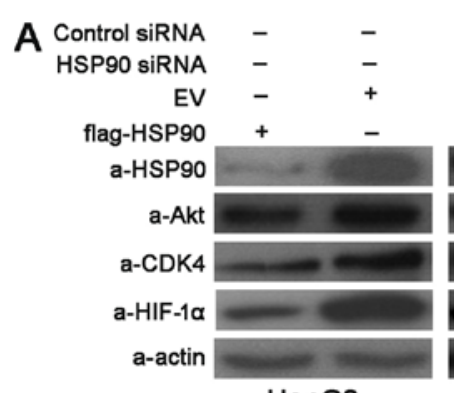

HepG2

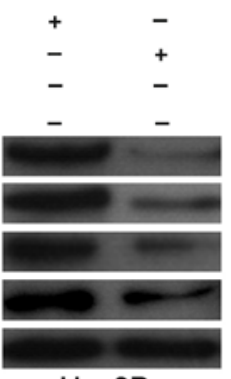

Нер3в

C
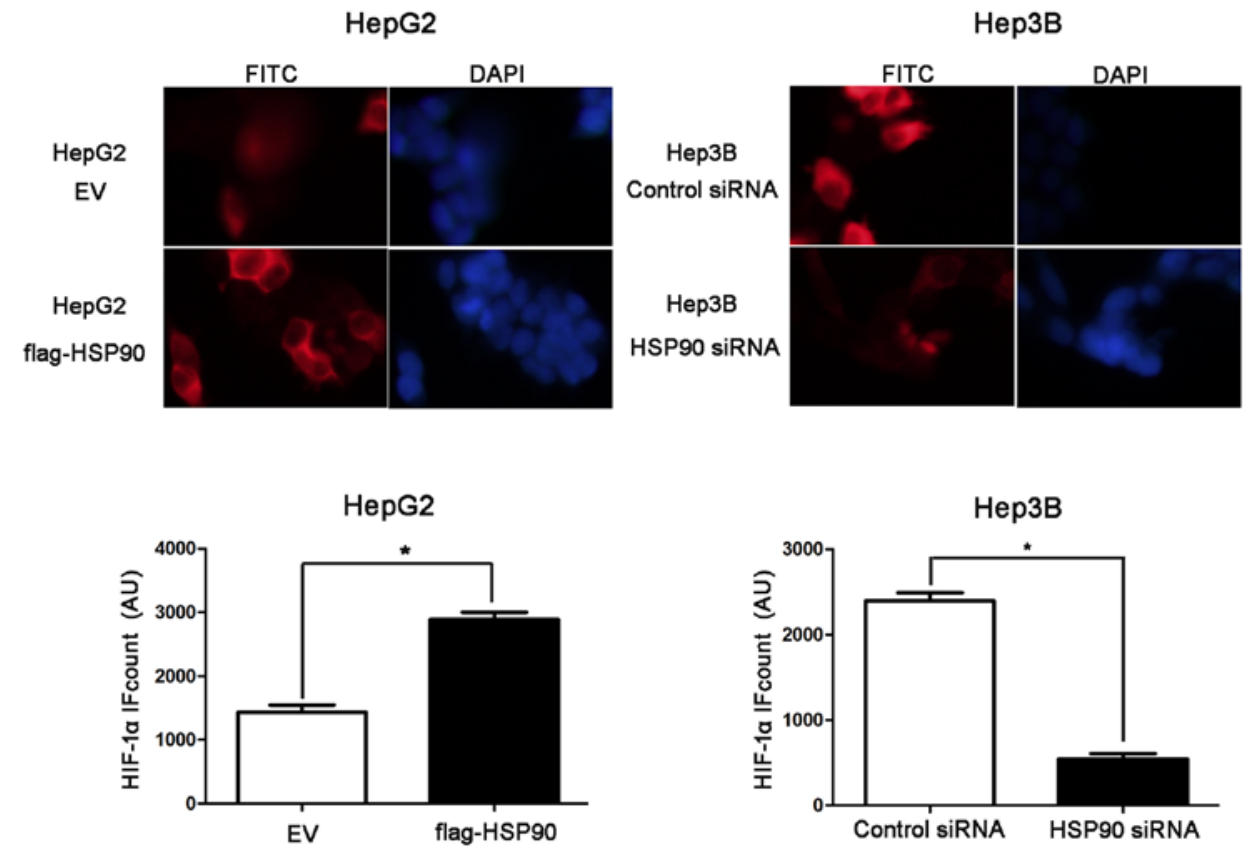

B

HepG2

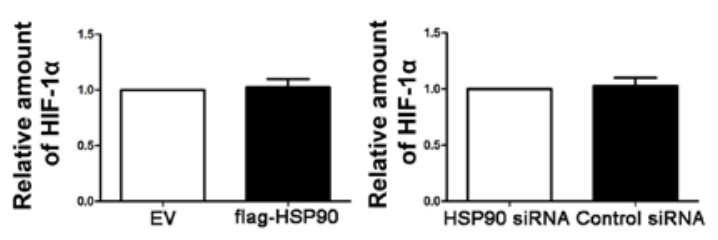

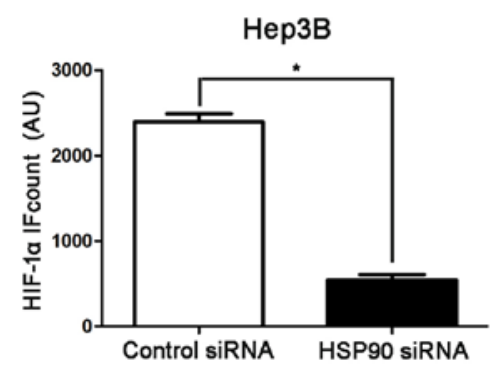

Figure 4. Heat shock protein (HSP) 90 regulates the abundance of the hypoxia-inducible factor (HIF)-1 $\alpha$ protein in hepatocellular carcinoma (HCC) cells. (A) Hep3B and HepG2 cells were transfected with HSP90 siRNA and Flag-HSP90, and then the cells were subjected to western blot analysis for HSP90, Akt, CDK4 and HIF-1 $\alpha$. HSP90 knockdown decreased Akt, CDK4 and HIF-1 $\alpha$ protein levels in Hep3B cells, whereas HSP90 overexpression led to Akt, CDK4 and HIF-1 $\alpha$ accumulation in HepG2 cells. Data are representative of multiple repeats with similar results. (B) EV or Flag-HSP90 were transfected into HepG2 cells and Hep3B cells were transfected with control siRNA or HSP90 siRNA and then these cells were harvested for RNA extraction and RT-qPCR. HSP90 knockdown or overexpression did not change HIF-1 $\alpha$ mRNA levels. $n=3$ independent experiment; values are depicted as the means \pm SEM. (C) HCC cells which were treated as (B) were subjected to immunofluorescence (IF) for HIF-1 $\alpha$. Quantification of HIF-1 $\alpha$ IF showed that the average level of HIF-1 $\alpha$ in the HSP90 siRNA-transfected Hep3B cells was significantly lower than that in the control cells and higher than that in the HSP90-overexpressing HepG2 cells. Scale bar, $20 \mu \mathrm{m}, \mathrm{n}=6$; values are depicted as the means $\pm \mathrm{SEM}$; ${ }^{\mathrm{P}}<0.05$ by t-test. 


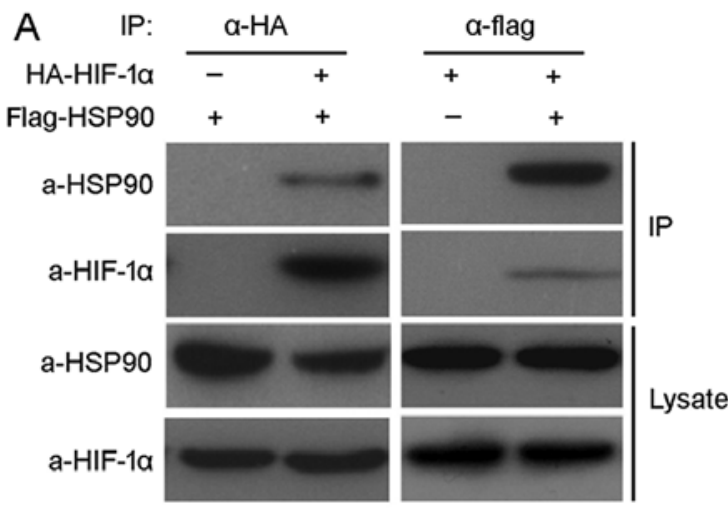

C

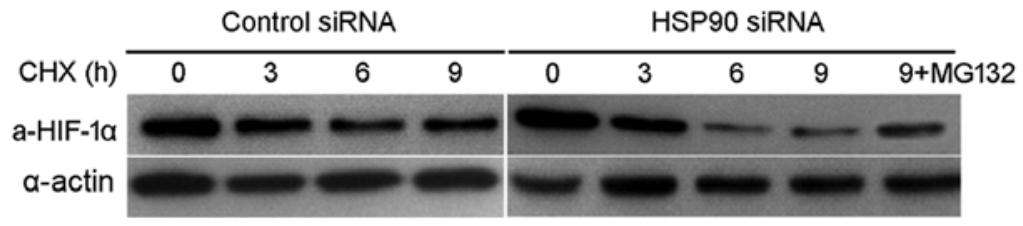

B
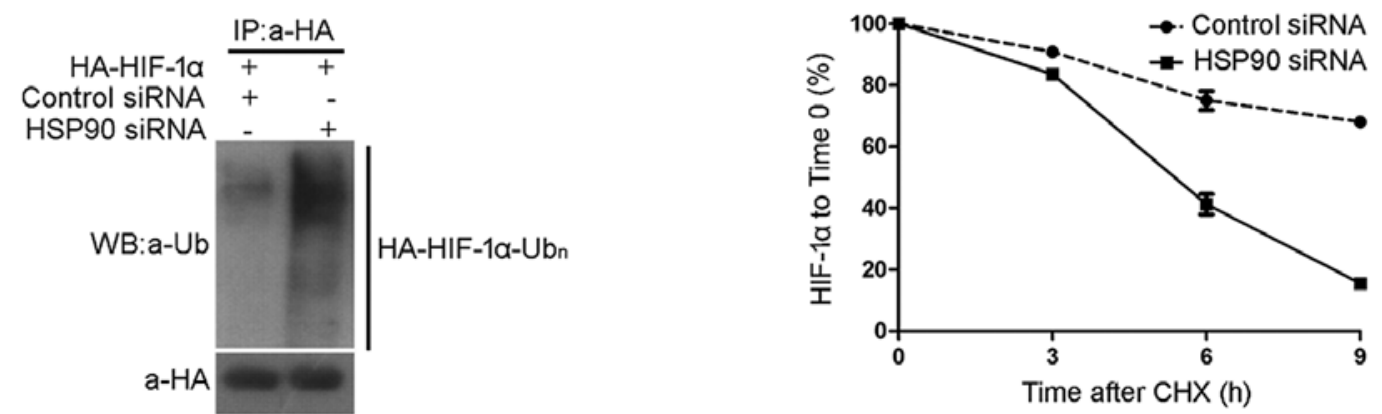

Figure 5. Heat shock protein (HSP) 90 binds to hypoxia-inducible factor (HIF)-1 $\alpha$ and inhibits the ubiquitination of HIF-1 $\alpha$. (A) HIF- $1 \alpha$ and HSP90 co-immunoprecipitate with each other. We transfected HA-HIF-1 $\alpha$ and Flag-HSP90 plasmids into HEK293 cells. HSP90 or HIF-1 $\alpha$ was immunoprecipitated with anti-Flag or anti-HA antibody. Western blot analysis was used to detect the specific proteins. (B) Using immunoprecipitation, we precipitated HA-HIF-1 $\alpha$ from HA-HIF-1 $\alpha$-overexpressing HepG2 cells using an anti-HA antibody. HIF-1 $\alpha$ ubiquitination was detected by western blot analysis. HSP90 knockdown promoted HIF-1 $\alpha$ ubiquitination. (C) The HIF-1 $\alpha$ turnover rate was shorter in HSP90 knockdown Hep3B cells. The protein half-life of HIF-1 $\alpha$ was analyzed after treating cells with cycloheximide (CHX). The HIF-1 $\alpha$ band intensity was normalized to GAPDH and then normalized to t=100 controls. The HIF-1 $\alpha$ turn-over rate was $100(\%)$ at the beginning. The half-life of HIF-1 $\alpha$ in HSP90 siRNA $=4.9 \mathrm{~h}\left(\mathrm{R}^{2}=0.94\right)$ and in $\mathrm{EV}=12.4 \mathrm{~h}\left(\mathrm{R}^{2}=0.94\right)$. In addition, treatment with MG132 inhibited HSP90 siRNA-induced HIF-1 $\alpha$ degradation in Hep3B cells. The data are representative of multiple independent experiments.

data suggest that HSP90 increases HIF-1 $\alpha$ protein levels in HCC cells.

HSP90 inhibits the ubiquitination and proteasomal degradation of $H I F-1 \alpha$. A previous study reported the identification of receptor for activated protein C kinasex1 (RACK1) as a novel HIF-1 $\alpha$-interacting protein (26). It was demonstrated that RACK1 promotes the $\mathrm{O}_{2} /$ prolyl hydroxylase domain (PHD)/von Hippel-Lindau (VHL)-independent and proteasome-dependent degradation of HIF-1 $\alpha$ (26). RACK1 competes with HSP90 for binding to the PAS-A domain of HIF-1 $\alpha$. RACK1 activity is required for the mechanisms of action of the HSP90 inhibitor, 17-allylaminogeldanamycin, to induce HIF-1 $\alpha$ degradation (26). In this study, to determine whether HSP90 binds to HIF-1 $\alpha$ and inhibits its ubiquitination and proteasomal degradation, we confirmed the interaction between HSP90 and HIF-1 $\alpha$ in 293 cells using co-IP of HA-HIF-1 $\alpha$ and Flag-HSP90 (Fig. 5A). In the next experiment investigating the precipitation of HA-HIF-1 $\alpha$ from HepG2 cells expressing HA-HIF-1 $\alpha$, HIF-1 $\alpha$ ubiquitination was detected by western blot analysis using an ubiquitin antibody. As shown in Fig. 5B, HSP90 knockdown increased the ubiquitination of HIF- $1 \alpha$ in the Hep3B cells. CHX is a protein synthesis inhibitor and CHX chase assays were performed in order to analyze the HSP90-mediated downregulation of HIF-1 $\alpha$ in the Hep3B cells in which HSP90 was knocked down and the controls. Compared with that observed in the control cells, the half-life of HIF-1 $\alpha$ was decreased in the cells in which HSP90 was knocked down (4.9 vs. 12.4 h; Fig. 5C; 12.4 is the average half-life of HIF-1 $\alpha$ ). Furthermore, MG132 (a proteasome inhibitor) was able to prevent the downregulation of HIF-1 $\alpha$ (Fig. 5C). These data suggest that HSP90 binds to HIF-1 $\alpha$ and thereby inhibits the ubiquitination and proteasomal degradation of HIF-1 $\alpha$.

HSP90 promotesthe proliferation and inhibits the apoptosis of HCC cells by inhibiting the degradation of HIF-1a. To determine whether HIF-1 $\alpha$ protein is involved in the HSP90 siRNA-induced growth arrest and apoptosis of HCC cells, the Hep3B cells in which HSP90 was knocked down were transfected with HA-HIF-1 $\alpha$. Unsurprisingly, the restoration of HIF- $1 \alpha$ expression in the Hep3B cells reversed the effects of HSP90 knockdown, which led to a significant decrease in the number of apoptotic cells and increased cell viability and proliferation $(\mathrm{P}<0.05$, respectively; Fig. 6). To determine whether HSP90 siRNA affected tumor growth by inhibiting HIF-1 $\alpha$, we used a mouse tumor model of Hep3B subcutaneous tumors. Firstly, the Hep3B cells were infected with different retroviruses, and these Hep3B cells were then implanted into nude mice by subcutaneous injection. After 21 days, tumor growth curves suggested that HSP90 siRNA attenuated Hep3B tumor growth in the mice. The restoration of HIF-1 $\alpha$ expression in the Hep3B cells in which HSP90 was knocked down partially restored tumor growth $(\mathrm{P}<0.05$; Fig. 7A). We performed IHC and TUNEL assays in the xenografted tissues. As expected, 

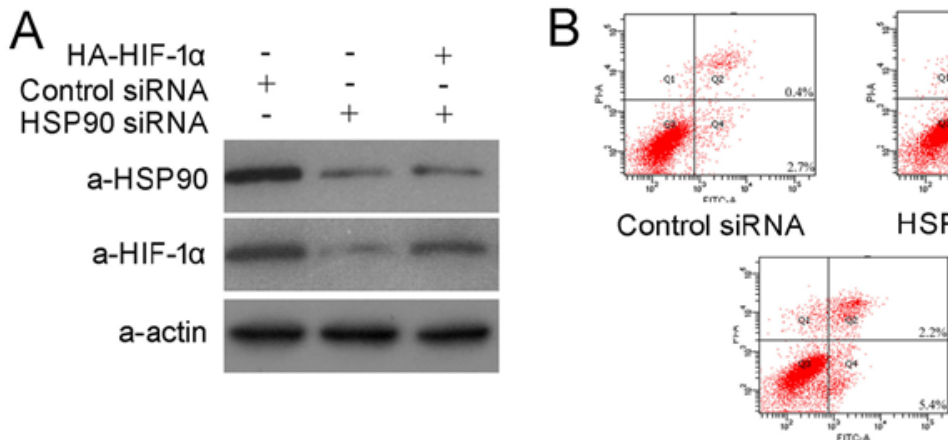

HSP90 siRNA+HA-HIF-1a

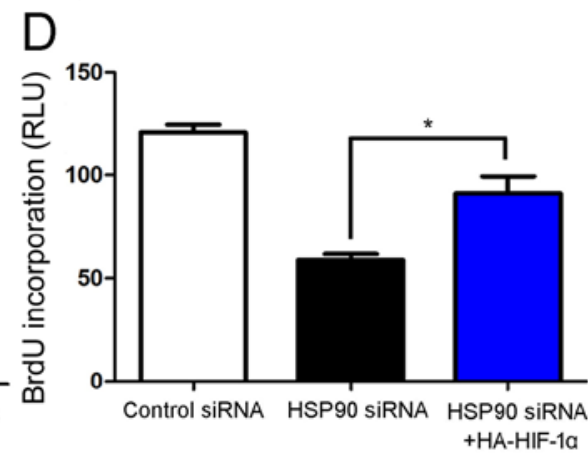

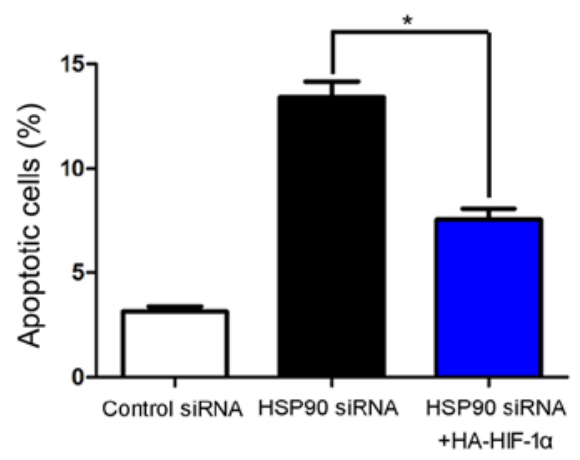

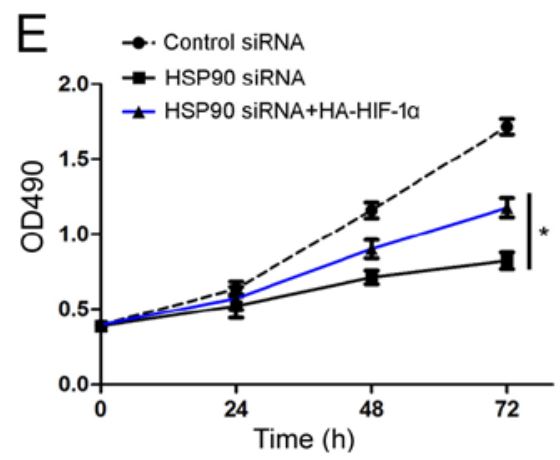

Figure 6. Heat shock protein (HSP)90 siRNA-induced suppression of Hep3B cell growth is partially reversed by hypoxia-inducible factor (HIF)-1 $\alpha$. (A) HSP90 siRNA-transfected Hep3B cells successfully downregulated HSP90 protein expression. HSP90 knockdown in Hep3B cells reduced the levels of HIF-1 $\alpha$. HSP90knockdown cells which were then transfected with HA-HIF-1 $\alpha$ partially rescued the HIF-1 $\alpha$ expression. The data are representative of multiple repeats with similar results. (B) Flow cytometry was used to measured apoptotic cells. Restoring HIF-1 $\alpha$ expression decreased the number of apoptotic cells in HSP90 siRNAtransfected Hep3B cells. "P<0.05 by one-way ANOVA; $n=3$ repeats with similar results. (C) In HSP90-knockdown Hep3B cells, the activity of the pro-apoptotic caspases-3 and -7 was decreased after HA-HIF-1 $\alpha$ transfection. " $\mathrm{P}<0.05$ by one-way ANOVA; $n=3$ repeats with similar results. (D) The results of BrdU assay suggested that HIF-1 $\alpha$ promoted proliferation in HSP90-knockdown Hep3B cells. "P $<0.05$ by one-way ANOVA; $\mathrm{n}=3$ repeats with similar results. (E) Performing MTT assays showed that HIF- $1 \alpha$ enhanced the viability of HSP90-knockdown Hep3B cells. " $\mathrm{P}<0.05$ by two-way ANOVA; $n=3$ repeats with similar results. Values are depicted as the means \pm SEM.

HSP90 siRNA induced apoptosis in vivo. The restoration of HIF-1 $\alpha$ expression partially abolished the inhibitory effects of HSP90 siRNA on HCC cell growth; it led to a significant reduction in the number of apoptotic cells $(\mathrm{P}<0.05$, respectively; Fig. 7B). In conclusion, these data indicate that HIF-1 $\alpha$ may act as a downstream factor in the HSP90-induced inhibition of apoptosis and the promotion of cell growth in HCC.

\section{Discussion}

The occurrence, metastasis, development and invasion of neoplasms result from interactions among multiple factors, polygenes and multi-stages (9). HSPs, also known as molecular chaperones, are essential for regulating intracellular protein balance with a highly conserved amino acid sequence (9). HSPs are involved in the final activation of several regulatory proteins (9). Based on the molecular weight, HSPs have been classified into several groups, including HSP70, HSP90 and HSP110 (27). HSP90 is mainly comprised of HSP90 $\beta$ and HSP90 $\alpha$. Furthermore, it has a molecular weight of $90 \mathrm{kDa}$, the largest part of which exists in glucose-regulated protein 94 (GRP94) of the endoplasmic reticulum and TNF receptor-associated protein (TRAP)1 of the mitochondria (28). Under physiological conditions, HSP90 accounts for $1-2 \%$ total proteins in cells; however, in a state of stress, its content increases by approximately 2-10 -fold. The protein and mRNA expression and levels of HSP90 have been shown to be upregulated in various types of cancers (9,29-32). In this study, we first examined the protein expression of HSP90 in samples from 60 patients with HCC using IF staining and western blot analysis, and our data demonstrated that HSP90 expression was significantly higher in the HCC tissues compared with that in matched normal tissues. In addition, HSP90 expression significantly correlated with venous infiltration, TNM tumor staging and Edmondson-Steiner grading, which is consistent with the results of our previous study (9). Furthermore, our data indicated that the negative expression of HSP90 significantly correlated with an improved 3-year patient survival for HCC patients, which is consistent with the results of previous studies on breast cancer, gastrointesinal stromal tumors and mesenchymal tumors $(33,34)$. Importantly, multivariate Cox repression analysis indicated that HSP90 is an independent factor for predicting overall 3-year survival in patients with HCC. These data suggested that HSP90 is crucial for the prognosis of patients with HCC. A previous study demonstrated that HSP90 acts as a tumor promoter which may be involved in the proliferation and apoptosis of HCC cells (35). The present study, further confirmed that HSP90 promotes tumor progression by accelerating tumor growth and inhibiting the apoptosis of HCC cells. 

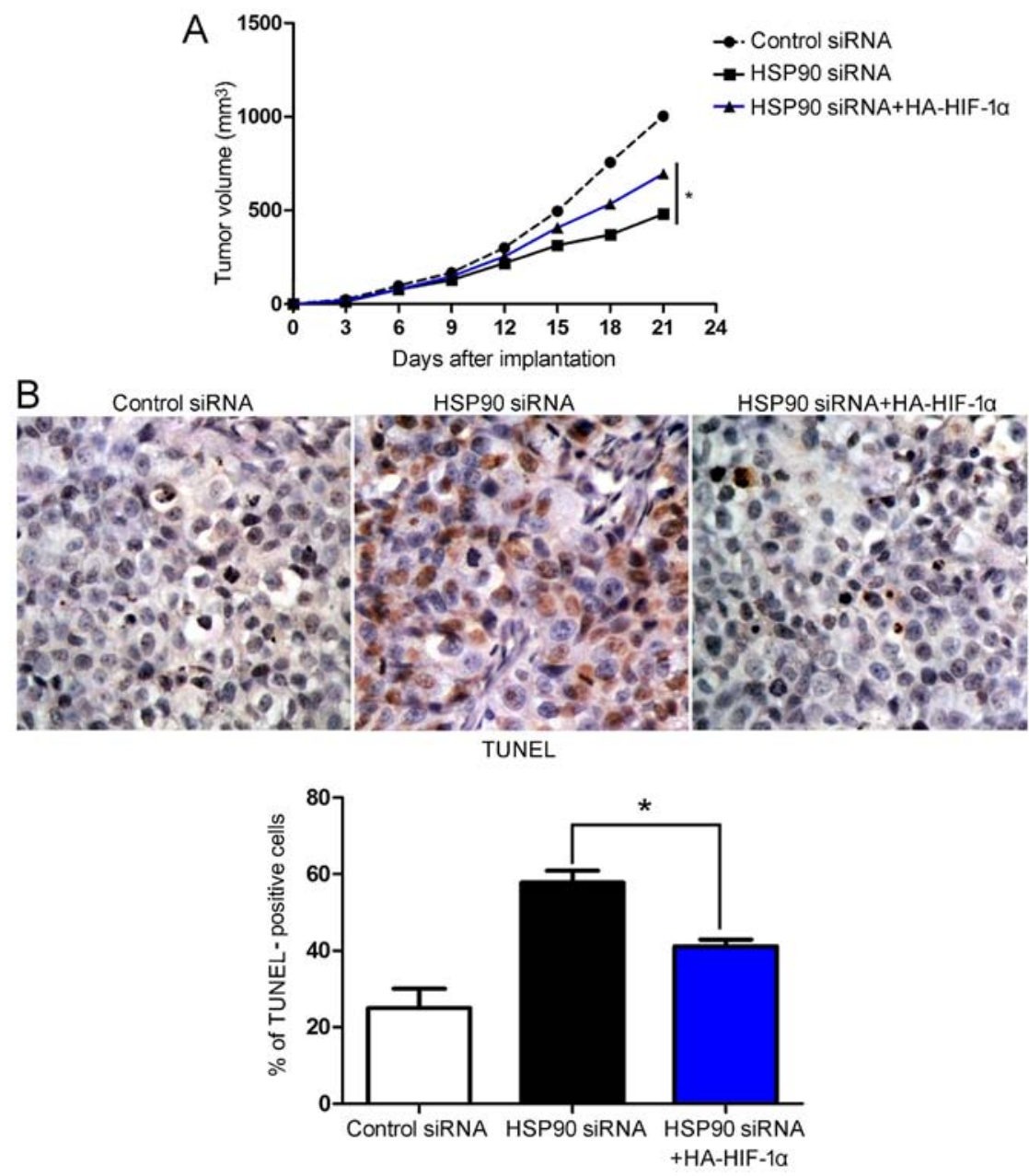

Figure 7. Hypoxia-inducible factor (HIF)-1 $\alpha$ partially abolishes heat shock protein (HSP) 90 siRNA-induced suppression of tumor growth. (A) Control Hep3B cells (control siRNA, n=6), HSP90-knockdown Hep3B cells (HSP90 siRNA, n=6) and co-expressing Hep3B cells (HSP90 + HA-HIF-1 $\alpha$, n=6), respectively, were implanted into nude mice by subcutaneous injection. A caliper was used to measure the tumor nodules at different times after implantation. HSP90-knockdown Hep3B cells exhibited a greater tumor-inhibiting effect than control cells; however, compared with the HSP90 siRNA group, restoring HIF-1 $\alpha$ expression promoted tumor growth. "P $<0.05$ by two-way ANOVA. (B) Tumor nodules were subjected to TUNEL assays and quantitative analysis. TUNEL assays showed that HSP90 knockdown markedly increased the percentage of apoptotic cells. Scale bar, $100 \mu \mathrm{m} ; \mathrm{n}=6$; values are depicted as the means $\pm \mathrm{SEM}$; ${ }^{*} \mathrm{P}<0.05$ and by one-way ANOVA.

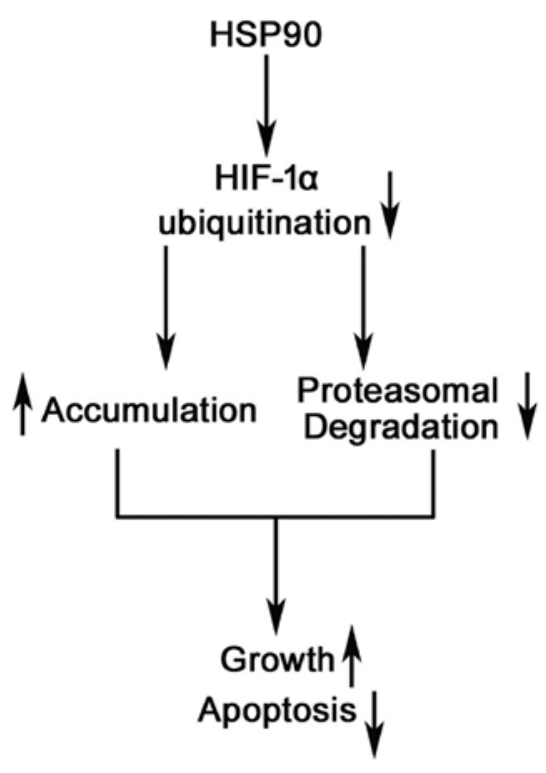

Figure 8. Working model for the tumor-promoting function of HSP90. HSP90 suppressed apoptosis and promoted the growth of HCC cells by inhibiting HIF-1 $\alpha$ proteasomal degradation and ubiquitination.
The prey or target proteins of HSP90 include urokinase and matrix metalloproteinase-2 (MMP-2) which are involved in the invasion and metastasis of tumor cells (9). It has been demonstrated that HIF is capable of maintaining revascularization (28). Furthermore, to inhibit the apoptosis of tumor cells, HIF-1 $\alpha$ regulates the function of tumor necrosis factor receptor (TNFR), protein kinase B (Akt) and nuclear factor- $\mathrm{\kappa B}$ (NF- $\mathrm{\kappa B})$ (28). Importantly, in our previous study, we reported that the HSP90 levels positively correlated with HIF-1 $\alpha$ in HCC tissues (9).

In the present study, we confirmed that HSP90 and HIF-1 $\alpha$ expression in the HCC tissues were higher compared with the expression levels in normal tumor-adjacent tissues. Furthermore, HSP90 was positively associated with HIF-1 $\alpha$ protein expression in the HCC tissues. In vitro experiments demonstrated that HSP90 positively regulated Akt and CDK4 abundance in the HCC cells. Notably, HSP90 overexpression induced a significant accumulation of HIF-1 $\alpha$ in the HepG2 cells. Conversely, the knockdown of HSP90 by siRNA in the Hep3B cells decreased the expression of the target genes, 
including Akt, CDK4 and HIF-1 $\alpha$. However, the HIF-1 $\alpha$ mRNA levels were not altered with HSP90 regulation, which suggested that HSP90 only regulated the level of the HIF-1 $\alpha$ protein in the HCC cells. The present study also revealed the positive interaction between HSP90 and HIF-1 $\alpha$ in 293 cells using co-IP. Furthermore, western blot analysis and co-IP indicated that HSP90 siRNA promoted HIF-1 $\alpha$ ubiquitination and shortened the half-life of HIF-1 $\alpha$ in the Hep3B cells, and that treatment with MG132 (a proteasome inhibitor) inhibited the downregulation of HIF-1 $\alpha$ by HSP90 siRNA. The data we present herein suggest that HSP90 inhibits the ubiquitination of HIF-1 $\alpha$ and its subsequent proteasomal degradation. However, further studies are required to confirm whether HIF-1 $\alpha$ is a target of HSP90, and we aim to address this issue using proteomic data with searches for HIF-1 $\alpha$ with HSP90 in the future.

In the present study, we demosntrated that the knockdown of HSP90 using siRNA led to the downregulation of HIF-1 $\alpha$ in vivo and in vitro. Furthermore, the observed increase in growth arrest and apoptosis which the knockdown of HSP90 resulted in, was partially reversed by the overexpression of HIF-1 $\alpha$. However, only less than half of the inhibitory effects of HSP90 siRNA on HCC cells were abolished, in spite of achieving more than half the restoration in the levels of HIF-1 $\alpha$. These data suggest that HIF- $1 \alpha$ is not the only downstream gene of HSP90 which inhibites apoptosis and promotes growth in HCC. As HSP90 targets many oncoproteins and subsequently regulates cell proliferation, the cell cycle and apoptosis, we suggest that HSP90 inhibits apoptosis and promotes growth by regulating HIF-1 $\alpha$. HSP90 suppresses the degradation of HIF- $1 \alpha$ and inhibits apoptosis and promotes growth in HCC.

In conclusion, in the present study, we have proven that increased levels of HSP90 are associated with poor clinicopathological characteristics in tissue samples of patients with HCC. In patients with HCC, the positive expression of HSP90 is an independent factor for predicting poor prognosis. HSP90 promotes growth and prevents apoptosis by inhibiting the ubiquitination and proteasomal degradation of the HIF-1 $\alpha$ protein (Fig. 8). Thus, we suggest that a gain of HSP90 function leads to hepatocarcinogenesis, partly through the accumulation of HIF- $1 \alpha$. We have identified HSP90 as a potential therapeutic target in HCC.

In conclusion, the findings of the present study demonstrated that the expression of HSP90 and HIF-1 $\alpha$ was markedly higher in the cancer tissues compared with the expression levels in the non-cancerous tissues, and that increased HSP90 levels correlated with poor clinicopathological characteristics in HCC. Furthermore, we have proven that HSP90 is an independent factor for predicting the overall 3-year survival in patients with HCC. In vitro experiments found that HSP90 promoted HCC cell growth by inhibiting apoptosis and promoting growth. HIF-1 $\alpha$ expression is positively associated with HSP90. Furthermore, our data indicate that HSP90 regulates HIF-1 $\alpha$ protein abundance by inhibiting the ubiquination and proteasomal degradation of HIF- $1 \alpha$ in HCC cells. Notably, the restoration of HIF-1 $\alpha$ partially abolished the inhibitory effects of HSP90 siRNA on HCC cell growth, which suggests that HSP90 may promote tumor growth by regulating the abundance of HIF-1 $\alpha$ protein. The data of our study reveal that HSP90 may have the potential to serve as a clinical biomarker and as a target for gene therapy in HCC.

\section{Acknowledgements}

The present study was supported by the National Natural Science Foundation of China (grant no. 81502092), the Zhejiang Provincial Natural Science Foundation of China (grant nos. LY16H160043 and LY13H150009) and the general project funds from the Health Department of Zhejiang province (grant nos. 2016KYA022 and 2015KYB033).

\section{References}

1. Buonaguro L, Petrizzo A, Tagliamonte M, Tornesello ML and Buonaguro FM: Challenges in cancer vaccine development for hepatocellular carcinoma. J Hepatol 59: 897-903, 2013.

2. Xu Q, Liu X, Zheng X, Yao Y, Wang M and Liu Q: The transcriptional activity of Gli1 is negatively regulated by AMPK through Hedgehog partial agonism in hepatocellular carcinoma. Int J Mol Med 34: 733-741, 2014.

3. Kiang JG and Tsokos GC: Heat shock protein $70 \mathrm{kDa}$ : molecular biology, biochemistry, and physiology. Pharmacol Ther 80: 183-201, 1998.

4. Welch WJ: Mammalian stress response: cell physiology, structure/function of stress proteins, and implications for medicine and disease. Physiol Rev 72: 1063-1081, 1992.

5. Milicevic Z, Bogojevic D, Mihailovic M, Petrovic M and Krivokapic Z: Molecular characterization of hsp90 isoforms in colorectal cancer cells and its association with tumour progression. Int J Oncol 32: 1169-1178, 2008.

6. Nimmanapalli R, O'Bryan E and Bhalla K: Geldanamycin and its analogue 17-allylamino-17-demethoxygeldanamycin lowers Bcr-Abl levels and induces apoptosis and differentiation of Bcr-Abl-positive human leukemic blasts. Cancer Res 61: 1799-1804, 2001.

7. Pascale RM, Simile MM, Calvisi DF, Frau M, Muroni MR, Seddaiu MA, Daino L, Muntoni MD, De Miglio MR, Thorgeirsson SS and Feo F: Role of HSP90, CDC37, and CRM1 as modulators of P16(INK4A) activity in rat liver carcinogenesis and human liver cancer. Hepatology 42: 1310-1319, 2005.

8. Yano M, Naito Z, Tanaka S and Asano G: Expression and roles of heat shock proteins in human breast cancer. Jpn J Cancer Res 87: 908-915, 1996.

9. Xu QR, Liu X, Yao YM and Liu QG: Expression of HSP90 and HIF-1 $\alpha$ in human colorectal cancer tissue and its significance. Asian Pac J Trop Med 7: 720-724, 2014.

10. Palsson-McDermott EM, Curtis AM, Goel G, Lauterbach MA, Sheedy FJ, Gleeson LE, van den Bosch MW, Quinn SR, DomingoFernandez R, Johnston DG, et al: Pyruvate kinase M2 regulates Hif- $1 \alpha$ activity and IL- $1 \beta$ induction and is a critical determinant of the Warburg effect in LPS-activated macrophages. Cell Metabolism $21: 65-80,2015$.

11. Wang GL,Jiang B-H,RueEA and Semenza GL:Hypoxia-inducible factor 1 is a basic-helix-loop-helix-PAS heterodimer regulated by cellular $\mathrm{O}_{2}$ tension. Proc Natl Acad Sci USA 92: 5510-5514, 1995.

12. Krishnamachary B, Berg-Dixon S, Kelly B, Agani F, Feldser D, Ferreira G, Iyer N, LaRusch J, Pak B, Taghavi P and Semenza GL: Regulation of colon carcinoma cell invasion by hypoxia-inducible factor 1. Cancer Res 63: 1138-1143, 2003.

13. Mizukami Y, Li J, Zhang X, Zimmer MA, Iliopoulos O and Chung DC: Hypoxia-inducible factor-1-independent regulation of vascular endothelial growth factor by hypoxia in colon cancer. Cancer Res 64: 1765-1772, 2004.

14. Cao D, Hou M, Guan YS, Jiang M, Yang Y and Gou HF: Expression of HIF-1alpha and VEGF in colorectal cancer: association with clinical outcomes and prognostic implications. BMC Cancer 9: 432, 2009.

15. Tu K, Yang W, Li C, Zheng X, Lu Z, Guo C, Yao Y and Liu Q: Fbxw7 is an independent prognostic marker and induces apoptosis and growth arrest by regulating YAP abundance in hepatocellular carcinoma. Mol Cancer 13: 110-110, 2014.

16. Riis ML, Lüders T, Nesbakken AJ, Vollan HS, Kristensen V and Bukholm IR: Expression of BMI-1 and Mel-18 in breast tissue - a diagnostic marker in patients with breast cancer. BMC Cancer 10: 686, 2010.

17. Tu K, Zheng X, Zan X, Han S, Yao Y and Liu Q: Evaluation of Fbxw7 expression and its correlation with the expression of c-Myc, cyclin E and p53 in human hepatocellular carcinoma. Hepatol Res 42: 904-910, 2012. 
18. Xu MZ, Yao TJ, Lee NP, Ng IO, Chan YT, Zender L, Lowe SW, Poon RT and Luk JM: Yes-associated protein is an independent prognostic marker in hepatocellular carcinoma. Cancer 115: 4576-4585, 2009.

19. Xu Q, Liu X, Zheng X, Yao Y and Liu Q: PKM2 regulates Gli1 expression in hepatocellular carcinoma. Oncol Lett 8: 1973-1979, 2014.

20. Tu K, Zheng X, Zhou Z, Li C, Zhang J, Gao J, Yao Y and Liu Q: Recombinant human adenovirus-p53 injection induced apoptosis in hepatocellular carcinoma cell lines mediated by p53-Fbxw7 pathway, which controls c-Myc and cyclin E. PLoS One 8: e68574, 2013.

21. Zheng X, Vittar NB, Gai X, Fernandez-Barrena MG, Moser CD, Hu C, Almada LL, McCleary-Wheeler AL, Elsawa SF, Vrabel AM and Shire AM: The transcription factor GLI1 mediates TGF $\beta 1$ driven EMT in hepatocellular carcinoma via a SNAI1-dependent mechanism. PLoS One 7: e49581, 2012.

22. Cao S, Yang S, Wu C, Wang Y, Jiang J and Lu Z: Protein expression of hypoxia-inducible factor-1 alpha and hepatocellular carcinoma: a systematic review with meta-analysis. Clin Res Hepatol Gastroenterol 38: 598-603, 2014.

23. Xue N, Jin J, Liu D, Yan R, Zhang S, Yu X and Chen $X$ Antiproliferative effect of HSP90 inhibitor Y306zh against pancreatic cancer is mediated by interruption of AKT and MAPK signaling pathways. Curr Cancer Drug Targets 14: 671-683, 2014

24. Haarberg HE, Paraiso KH, Wood E, Rebecca VW, Sondak VK Koomen JM and Smalley KS: Inhibition of Wee1, AKT, and CDK4 underlies the efficacy of the HSP90 inhibitor XL888 in an in vivo model of NRAS-mutant melanoma. Mol Cancer Ther 12: 901-912, 2013

25. Lu XG, Xing CG, Feng YZ, Chen J and Deng C: Clinical significance of immunohistochemical expression of hypoxia-inducible factor-1alpha as a prognostic marker in rectal adenocarcinoma. Clin Colorectal Cancer 5: 350-353, 2006.

26. Liu YV and Semenza GL: RACK1 vs. HSP90: competition for HIF-1 alpha degradation vs. stabilization. Cell Cycle 6: 656-659, 2007.
27. Bagatell R and Whitesell L: Altered Hsp90 function in cancer: a unique therapeutic opportunity. Mol Cancer Ther 3: 1021-1030, 2004.

28. Goetz MP, Toft DO, Ames MM and Erlichman C: The Hsp90 chaperone complex as a novel target for cancer therapy. Ann Oncol 14: 1169-1176, 2003.

29. Whitesell L and Lindquist SL: HSP90 and the chaperoning of cancer. Nat Rev Cancer 5: 761-772, 2005.

30. Workman P, Burrows F, Neckers L and Rosen N: Drugging the cancer chaperone HSP90: Combinatorial therapeutic exploitation of oncogene addiction and tumor stress. Ann NY Acad Sci 1113: 202-216, 2007.

31. Qi XL, Bo AH, Yue SC, Wang CY and Liu HB: Heat shock protein 90 mrna expressed in adenocarcinoma and adenoma of significance. Proceed Military Academy Medical Sci 30: 351-353, 2011

32. Bo AH, Dai J, Li SG, Zuo DS, Chen XL, Yan YJ, et al: HSP90 mRNA expressed in stomach and large intestine cancer research. Chin J Histochem Cytochem 14: 213-216, 2011

33. Pick E, Kluger Y, Giltnane JM, Moeder C, Camp RL, Rimm DL and Kluger HM: High HSP90 expression is associated with decreased survival in breast cancer. Cancer Res 67: 2932-2937, 2007.

34. Kang GH, Lee EJ, Jang KT, Kim KM, Park CK, Lee CS, Kang DY, Lee SH, Sohn TS and Kim S: Expression of HSP90 in gastrointestinal stromal tumours and mesenchymal tumours. Histopathology 56: 694-701, 2010.

35. Zhao S,LiH, Jiang C,Ma T, Wu C,Huo Q and Liu H: 17-Demethoxyreblastatin, an Hsp90 inhibitor, induces mitochondria-mediated apoptosis through downregulation of Mcl-1 in human hepatocellular carcinoma cells. J Bioenerg Biomembr 47: 373-381, 2015. 